\title{
An Hepatitis C Virus (HCV)/HIV Co-Infected Patient who Developed Severe Hepatitis during Chronic HCV Infection: Sustained Viral Response with Simeprevir Plus Peginterferon-Alpha and Ribavirin
}

\author{
Noboru Hirashima ${ }^{1}$, Hiroaki Iwase ${ }^{1}$, Masaaki Shimada ${ }^{1}$, Junji Imamura $^{2}$, Wataru Sugiura ${ }^{2}$, \\ Yoshiyuki Yokomaku ${ }^{2}$ and Tsunamasa Watanabe ${ }^{2,3}$
}

\begin{abstract}
We herein describe the case of a 42-year-old man who developed severe hepatitis caused by hepatitis C virus $(\mathrm{HCV})$ infection at 14 years after the start of human immunodeficiency virus (HIV) treatment. Surprisingly, the levels of alanine aminotransferase (ALT) fluctuated, reaching a peak higher than 1,000 IU/L during chronic HCV infection, and the hepatic histology showed advanced liver fibrosis at 3 years after the primary $\mathrm{HCV}$ infection. He was treated with simeprevir, peginterferon-alpha, and ribavirin with a sustained viral response. We conclude that HCV/HIV co-infected patients need to commence anti-HCV therapy when the levels of ALT fluctuate severely under successful HIV control.
\end{abstract}

Key words: hepatitis C virus, human immunodeficiency virus, co-infection, simeprevir, peginterferon-alpha, severe hepatitis

(Intern Med 54: 2173-2177, 2015)

(DOI: 10.2169/internalmedicine.54.4344)

\section{Introduction}

Co-infection with hepatitis $\mathrm{C}$ virus (HCV) and human immunodeficiency virus (HIV) is common, as both viruses share similar modes of transmission (1). Although injection drug use (IDU) remains the main route of $\mathrm{HCV}$ infection, recent studies have shown that $\mathrm{HCV}$ can be sexually transmitted in the absence of IDU, particularly among HIVpositive men who have sex with men (MSM) (2-5). In general, the progression of HCV-related liver diseases is accelerated in HCV/HIV co-infected individuals $(6,7)$. HCV has emerged as an important cause of morbidity and mortality in co-infected patients (8) because successful combination antiretroviral therapy (cART) has dramatically changed the prognosis of HIV-infected individuals (9). The consequences of HCV/HIV co-infection are less spontaneous clearance (10), higher rates of chronicity, accelerated fibrosis progression with increased risk of cirrhosis $(11,12)$ and hepatocellular carcinoma (13) resulting in higher liver-related mortality, and decreased HCV treatment response $(14,15)$. The management of HCV infection among the HIV-infected population poses a serious challenge for physicians. Recently, a better sustained viral response (SVR) has been seen following combination therapy of $\mathrm{HCV}$ protease inhibitor simeprevir and peginterferon-alpha/ribavirin (PegIFNo/ RBV) (16). This combination therapy may be a suitable treatment regimen for $\mathrm{HCV}$-positive Japanese patients because the interferon-resistant $\mathrm{HCV}$ genotype $1 \mathrm{~b}$ is more common in Japan (17). This report herein describes a case of a MSM who developed severe hepatitis caused by chronic HCV infection while under successful cART, and who achieved SVR through HCV treatment with simeprevir and PegIFN $\alpha / R B V$.

\footnotetext{
${ }^{1}$ Department of Gastroenterology, National Hospital Organization Nagoya Medical Center, Japan, ${ }^{2}$ Department of Infectious Diseases and Immunology Clinical Research Center, National Hospital Organization Nagoya Medical Center, Japan and ${ }^{3}$ Department of Virology and Liver Unit, Nagoya City University Graduate School of Medical Sciences, Japan

Received for publication October 22, 2014; Accepted for publication December 25, 2014

Correspondence to Dr. Tsunamasa Watanabe, twatanab@marianna-u.ac.jp
} 
Table. Laboratory Data before Treatment of Hepatitis C.

\begin{tabular}{|c|c|c|c|c|c|}
\hline \multicolumn{2}{|c|}{ Blood cells } & \multicolumn{2}{|c|}{ Blood chemistry } & \multicolumn{2}{|r|}{ Serological test } \\
\hline RBCs & $557 \times 10^{4} / \mu \mathrm{L}$ & Albumin & $4.4 \mathrm{~g} / \mathrm{dL}$ & HBs antigen & $0.01 \mathrm{mIU} / \mathrm{mL}$ (negative) \\
\hline Hemoglobin & $16.2 \mathrm{~g} / \mathrm{dL}$ & AST & $32 \mathrm{IU} / \mathrm{L}$ & HBs antibody & $219.93 \mathrm{mIU} / \mathrm{mL}$ (positive) \\
\hline WBCs & $5,200 / \mu \mathrm{L}$ & Alkaline phosphatase & $187 \mathrm{IU} / \mathrm{L}$ & HBV DNA & not detected \\
\hline Neutrophils & $55.9 \%$ & $\gamma$-glutamyl transferase & $112 \mathrm{IU} / \mathrm{L}$ & $\mathrm{HCV}$ antibody & 10.69 Sample/c (positive) \\
\hline Lymphocytes & $29.6 \%$ & Total bilirubin & $1.4 \mathrm{mg} / \mathrm{dL}$ & HCV serotype & undetermined \\
\hline CD4 cells & $376 / \mu \mathrm{L}$ & Creatinine & $0.79 \mathrm{mg} / \mathrm{dL}$ & HIV-1 RNA & not detected \\
\hline CD4/CD8 ratio & 1.0 & Hyaluronic acid & $148 \mathrm{ng} / \mathrm{mL}(<50)$ & IL $28 B$ SNP & Major homo \\
\hline PT (INR) & 1.24 & PIIINP & $1.2 \mathrm{U} / \mathrm{mL}(<1.0)$ & $\alpha$ fetoprotein & $6 \mathrm{ng} / \mathrm{mL}$ \\
\hline & & Type IV collagen $7 \mathrm{~S}$ & $8.4 \mathrm{ng} / \mathrm{mL}(<6.0)$ & PIVKA II & $24 \mathrm{mAU} / \mathrm{mL}$ \\
\hline
\end{tabular}

RBC: red blood cell, WBC: white blood cell, AST: aspartate aminotransferase, ALT: alanine aminotransferase, PIIINP: amino-terminal properties of type III collagen, PT (INR): prothrombin time (International Normalized Rate)

\section{Case Report}

A 42-year-old Japanese man was diagnosed with an HIV1 infection at our hospital in August 1997. He is a MSM and had no other risk of liver damage (e.g., ingestion of alcohol or the presence of diabetes mellitus). At his initial laboratory examination, his HIV-1 viral load was 75,000 copies (3.8 log copies)/mL, and his CD4-positive cell count was $160 / \mu \mathrm{L}$. The patient began treatment with two nucleoside analogue reverse transcriptase inhibitors (NRTIs) in 1997, which was common before treatment with cART was established and is now contraindicated. Nelfinavir was added to his treatment regimen after its approval by the Japanese Ministry of Health and Welfare in 1998; however, this treatment failed because of viral drug resistance. The nelfinavirrelated resistant amino acid mutation $\mathrm{D} 30 \mathrm{~N}$ was detected on his HIV drug resistance test. The subsequent regimen consisted of didanosine (ddl), abacavir (ABC), and ritonavirboosted atazanavir; these drugs were selected for salvage treatment and afterwards, the virus was well controlled. In 2011, the cART regimen was updated to $\mathrm{ABC}$, etravirine (ETR), and raltegravir (RAL) to aid in preventing ddl longterm toxicity, lactic acidosis due to mitochondria injury, lipodystrophy, neuropathy, and portal vein embolization. The patient's HIV viral load was undetectable and his CD4 count was maintained above $350 / \mu \mathrm{L}$ for 15 years after the salvage treatment was initiated. At 14 years after the introduction of antiretroviral treatment, his alanine aminotransferase (ALT) and aspartate aminotransferase (AST) levels rose to $601 \mathrm{IU} / \mathrm{L}$ and $268 \mathrm{IU} / \mathrm{L}$, respectively, and the anti$\mathrm{HCV}$ antibody was seroconverted, thus leading to the clinical diagnosis of acute HCV infection. There was no evidence of hepatitis A, B, D, or E infection, or evidence of other causes of haptic cytolysis; the patient reported having had unprotected receptive anal intercourse with multiple men the previous year but had never injected illicit drugs. His HCV RNA load was $6.3 \log \mathrm{IU} / \mathrm{mL}$, however, the HCV serotype was indeterminable. One month after the onset of acute hepatitis, his ALT level decreased to under $200 \mathrm{IU} / \mathrm{L}$ and further decreased to less than $100 \mathrm{IU} / \mathrm{L}$ after 4 months.
Because his platelet count was over $180,000 / \mu \mathrm{L}$ and the noninvasive biomarkers of liver fibrosis $(18,19)$ did not indicate advanced liver fibrosis [hyaluronic acid: $60.7 \mu \mathrm{g} / \mathrm{L}$ (normal: $<50 \mu \mathrm{g} / \mathrm{L}$ ), amino-terminal properties of type III collagen: $1.1 \mathrm{U} / \mathrm{mL}$ (normal: $<1.0 \mathrm{U} / \mathrm{mL}$ ), type IV collagen $7 \mathrm{~S}: 5.3 \mathrm{ng} / \mathrm{mL}$ (normal: $<6.0 \mathrm{ng} / \mathrm{mL}$ )], the HCV treatment was suspended until direct-acting antivirals (DAAs), which are highly effective, well-tolerated therapies (20), were approved by the Japanese Ministry of Health, Labour and Welfare. Two years after the onset of his primary HCV infection, the patient's liver transaminases were again elevated (ALT 1,100 IU/L, AST $541 \mathrm{IU} / \mathrm{L}$ ) and the exacerbation of his HCV infection was supported by HCV RNA fluctuations (his HCV load was 6.2 to $7.2 \log \mathrm{IU} / \mathrm{mL}$ ). A percutaneous liver biopsy was performed 3 years after the diagnosis of his primary $\mathrm{HCV}$ infection and indicated advanced fibrosis with active hepatitis (grade 3 inflammation and stage 3 fibrosis based on the New Inuyama Classification), but no steatohepatitis or other type of liver injury was observed. The patient was treated with simeprevir and PegIFN $\alpha-2 b / R B V$ for 24 weeks while estimating the presence of $\mathrm{HCV}$ genotype 1 infection, because the result of HCV serotyping by an enzyme-linked immunosorbent assay using group-specific recombinant peptides for the NS4 region (21) was undetermined. The cART regimen was changed to rilpivirine $(\mathrm{RPV}) / \mathrm{RAL}$ for HCV treatment, because both RPV and RAL have relatively few drug-drug interactions with simeprevir. The patient achieved SVR without severe complications (including possible HIV virological rebound) and his ALT level returned to within the normal range. The laboratory data before the start of HCV therapy is summarized in Table. IL28B single nucleotide polymorphisms (TT genotype) were found (22). The overview of the clinical course of our case is shown in Figure.

\section{Discussion}

Elevated ALT levels against primary HCV infection are reported to be mild and relatively transient in HIV-infected MSM (23). The present case is a MSM who showed HCV seroconversion with a high ALT level (elevated to $601 \mathrm{IU} / \mathrm{L}$ ) 


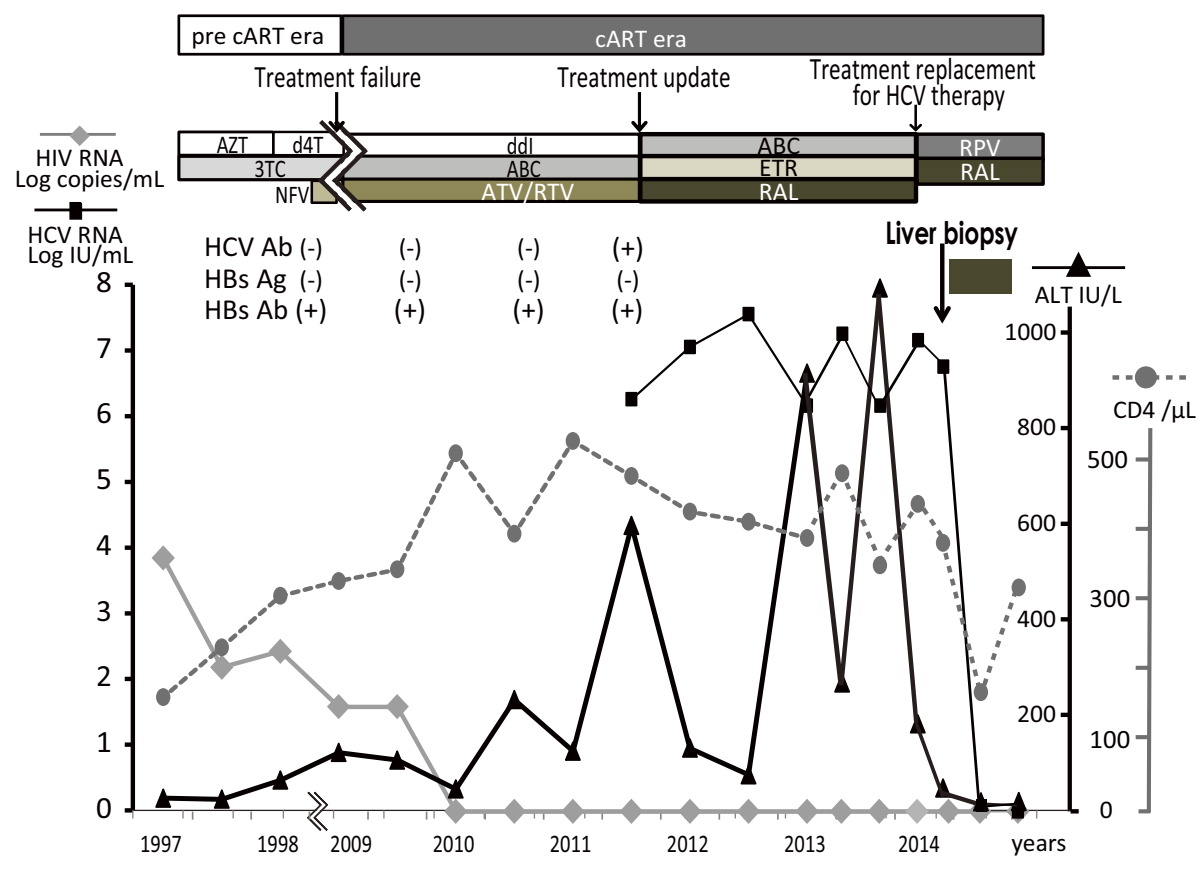

Simeprevir with PegIFN $\alpha /$ RBV AZT: azitotimidine, 3TC: lamivudine, d4T: sanilvudine, NFV: nelfinavir ddl: didanosine, ABC: abacavir, ATV: atazanavir, RTV: ritonavir, ETR: etravirine, RAL: raltegravir, RPV: rilpivirine

Figure. The clinical course of our case.

under successful cART. Surprisingly, his ALT levels fluctuated and elevated to over 1,000 IU/L 2 years after his primary HCV infection. In general, chronic hepatitis caused by HCV mono-infection exhibits a mild increase in ALT, rarely over $300 \mathrm{IU} / \mathrm{L}$, because $\mathrm{HCV}$-specific T-cell responses became dysfunctional over several months after the primary infection $(24,25)$. Moreover, during HIV infection, impaired CD4+ T-cells function and the subsequent depletion of CD4+ T-cells, as a result of continuous CD4+ cell destruction, is thought to be a cause of the profound impaired cellular immune response which has an important role in viral hepatitis. However, in this HCV/HIV co-infected patient, his liver inflammation two years after the primary HCV infection represented severe hepatitis (ALT levels peaking at > 1,000 IU/L) beyond the chronic HCV mono-infected conditions. These findings indicated that the immune responses against HCV infection could not completely recover in HIVinfected individuals even after long-term treatment with successful cART regimens. HIV infection is well known as an immune suppressive disease but its essentially an immune disorder. Many clinicians actually face diverse immune disorders, including not only immune suppressive disease characterized by a susceptibility to infection with opportunistic pathogens, but also autoimmune diseases (such as thyroid diseases, psoriasis, systemic lupus erythematodes, and inflammatory bowel syndrome) after the immune system recovers following cART. The causes of induced autoimmune diseases remain unknown, however, it is believed that functional impairments on regulatory T-cells (Tregs), sustained even after starting cART, contributes to induce dysregulated inflammation. Therefore, we hypothesize that the reason for a strong cellular immune response during HIV infection is due to the fact that CD4+ Tregs can be infected with HIV1 (26), and the Treg function may not have fully recovered even though the patient's HIV infection had been well controlled by successful cART regimens for more than 15 years. Although direct evidence for this hypothesis is lacking, it was previously reported that impaired Treg function may have detrimental consequences for the control of $\mathrm{HCV}$ immune activation (27) and accelerated fibrosis progression. Indeed, our patient's hepatic histology 3 years after the primary $\mathrm{HCV}$ infection presented as F3 (pre-cirrhosis stage), indicating the very rapid progression of liver fibrosis from the $\mathrm{HCV}$ infection in an $\mathrm{HIV}$-infected individual even though the CD4+ T-cell counts recovered. Therefore, careful monitoring for the rapid progression of hepatitis $\mathrm{C}$ is required for HIV-infected individuals even after successful HIV control.

In HCV/HIV co-infected patients, cART has shown to delay the progression of liver cirrhosis (28), and those with undetectable HIV RNA levels tend to have slower cirrhosis progression than those with detectable viremia (29). However, in the present case, the HIV RNA levels were repeatedly undetectable, and the hepatic histology showed the development of pre-cirrhosis due to severe liver inflammation. Therefore, treating the HCV with active hepatitis was required to halt the fibrosis progression. The response to treatment with PegIFN $\alpha / \mathrm{RBV}$ in $\mathrm{HCV} / \mathrm{HIV}$ co-infected patients is poorer than that of patients with $\mathrm{HCV}$ mono-infection. In fact, the SVR rate is reported to be $27-29 \%(30-32)$ in co- 
infected patients compared with $42-46 \%(33,34)$ in $\mathrm{HCV}$ genotype 1 mono-infections. It is expected that DAA will be a good therapy for HCV/HIV co-infected individuals. Coinfected patients receiving concurrent HIV and HCV treatment, however, are faced with the difficulty of proper treatment regimen selection, such as an increased risk of drugdrug interactions and drug-induced liver injury, particularly among those with advanced liver disease (35). HIV integrase inhibitors (i.e., RAL) have relatively few drug-drug interactions, whereas the use of HIV protease inhibitors and nonnucleoside reverse transcriptase inhibitor (NNRTI), except RPV, might preclude the use of some HCV DAA agents, particularly those targeting $\mathrm{HCV}$ protease. The patients are sometimes forced to change cART regimens because HCV proteases are metabolized through CYP3A4 and HIV protease inhibitors and NNRTIs interfere with the CYP3A4 activity, which may affect the HCV protease blood concentration. Therefore, we selected RAL and RPV as the NRTIsparing regimen, because RPV has fewer drug-drug interactions and this combination is effective for HIV suppression with minimal side effects. In a phase II study, treatment with telaprevir (a first-generation $\mathrm{HCV}$ NS3/4A protease inhibitor) and PegIFN $\alpha /$ RBV for 48 weeks led to significantly greater responses in $\mathrm{HCV} / \mathrm{HIV}$ co-infected patients, with SVR rates of $74 \%$ (36). The second-generation HCV protease inhibitor simeprevir, a once-daily HCV protease inhibitor with more favorable tolerability, has also been studied in co-infected populations. When given for 12 weeks in combination with PegIFN $\alpha / R B V$ to co-infected individuals with HCV genotype 1, the overall SVR at 12 weeks was $74 \%$ (37). Because simeprevir can interact with HIV protease inhibitors and efavirenz (an NNRTI), most patients in that study were placed on RAL-based cART.

For many patients, it is clear that there is a benefit to waiting for the approval of new DAA agents as interferonfree treatment regimens. However, immediate HCV therapy should be strongly considered for co-infected patients with advanced fibrosis or active hepatitis. For HCV treatmentnaive co-infected patients, we recommend that immediate cART initiation should be considered and the degree of fibrosis should be examined in each patient. A liver biopsy may be required for the co-infected patients, because reduced platelet counts are more commonly observed among patients infected with HIV $(38,39)$ and noninvasive scoring systems are still in the early use in HIV co-infected patients.

In conclusion, HCV/HIV co-infected patients under successful HIV control, especially those with primary HCV infection after HIV infection, must be carefully monitored to evaluate both the progression of hepatitis and the initiation of anti-HCV therapy, even if the noninvasive biomarkers of liver fibrosis indicate decreased fibrosis.

The authors state that they have no Conflict of Interest (COI).

\section{References}

1. Alter MJ. Epidemiology of viral hepatitis and HIV co-infection. J Hepatol 44: S6-S9, 2006.

2. Urbanus AT, van de Laar TJ, Stolte IG, et al. Hepatitis C virus infections among HIV-infected men who have sex with men: an expanding epidemic. AIDS 23: F1-F7, 2009.

3. van de Laar T, Pybus $\mathrm{O}$, Bruisten $\mathrm{S}$, et al. Evidence of a large, international network of $\mathrm{HCV}$ transmission in HIV-positive men who have sex with men. Gastroenterology 136: 1609-1617, 2009.

4. Matthews GV, Pham ST, Hellard M, et al. Patterns and characteristics of hepatitis $\mathrm{C}$ transmission clusters among HIV-positive and HIV-negative individuals in the Australian trial in acute hepatitis C. Clin Infect Dis 52: 803-811, 2011.

5. Fierer DS, Dieterich DT, Fiel MI, et al. Rapid progression to decompensated cirrhosis, liver transplant, and death in HIV-infected men after primary hepatitis $C$ virus infection. Clin Infect Dis 56: 1038-1043, 2013.

6. Thein HH, Yi Q, Dore GJ, Krahn MD. Natural history of hepatitis $\mathrm{C}$ virus infection in HIV-infected individuals and the impact of HIV in the era of highly active antiretroviral therapy: a metaanalysis. AIDS 22: 1979-1991, 2008.

7. Martin-Carbonero L, Benhamou Y, Puoti M, et al. Incidence and predictors of severe liver fibrosis in human immunodeficiency virus-infected patients with chronic hepatitis C: a European collaborative study. Clin Infect Dis 38: 128-133, 2004.

8. Chen TY, Ding EL, Seage Iii GR, Kim AY. Meta-analysis: increased mortality associated with hepatitis C in HIV-infected persons is unrelated to HIV disease progression. Clin Infect Dis 49 : 1605-1615, 2009.

9. Kitahata MM, Gange SJ, Abraham AG, et al. Effect of early versus deferred antiretroviral therapy for HIV on survival. N Engl J Med 360: 1815-1826, 2009.

10. Sulkowski MS. Hepatitis C virus infection in HIV-infected patients. Curr Infect Dis Rep 3: 469-476, 2001.

11. Pineda JA, Romero-Gomez M, Diaz-Garcia F, et al. HIV coinfection shortens the survival of patients with hepatitis $\mathrm{C}$ virus-related decompensated cirrhosis. Hepatology 41: 779-789, 2005.

12. Pineda JA, Aguilar-Guisado M, Rivero A, et al. Natural history of compensated hepatitis C virus-related cirrhosis in HIV-infected patients. Clin Infect Dis 49: 1274-1282, 2009.

13. Brau N, Fox RK, Xiao P, et al. Presentation and outcome of hepatocellular carcinoma in HIV-infected patients: a U.S.-Canadian multicenter study. J Hepatol 47: 527-537, 2007.

14. Torriani FJ, Rodriguez-Torres M, Rockstroh JK, et al. Peginterferon Alfa-2a plus ribavirin for chronic hepatitis $\mathrm{C}$ virus infection in HIV-infected patients. N Engl J Med 351: 438-450, 2004.

15. Rodriguez-Torres M, Slim J, Bhatti L, et al. Peginterferon alfa-2a plus ribavirin for HIV-HCV genotype 1 coinfected patients: a randomized international trial. HIV Clin Trials 13: 142-152, 2012.

16. Jacobson IM, Dore GJ, Foster GR, et al. Simeprevir with pegylated interferon alfa 2a plus ribavirin in treatment-naive patients with chronic hepatitis $\mathrm{C}$ virus genotype 1 infection (QUEST-1): a phase 3, randomised, double-blind, placebo-controlled trial. Lancet 384: 403-413, 2014.

17. Izumi $\mathrm{N}$, Hayashi $\mathrm{N}$, Kumada $\mathrm{H}$, et al. Once-daily simeprevir with peginterferon and ribavirin for treatment-experienced HCV genotype 1-infected patients in Japan: the CONCERTO-2 and CONCERTO-3 studies. J Gastroenterol 49: 941-953, 2014.

18. Stauber RE, Lackner C. Noninvasive diagnosis of hepatic fibrosis in chronic hepatitis C. World J Gastroenterol 13: 4287-4294, 2007.

19. Cacoub P, Carrat F, Bedossa P, et al. Comparison of non-invasive liver fibrosis biomarkers in $\mathrm{HIV} / \mathrm{HCV}$ co-infected patients: the fibrovic study--ANRS HC02. J Hepatol 48: 765-773, 2008.

20. Chatel-Chaix L, Germain MA, Gotte M, Lamarre D. Direct-acting 
and host-targeting HCV inhibitors: current and future directions. Curr Opin Virol 2: 588-598, 2012.

21. Tanaka T, Tsukiyama-Kohara K, Yamaguchi K, et al. Significance of specific antibody assay for genotyping of hepatitis $\mathrm{C}$ virus. Hepatology 19: 1347-1353, 1994.

22. Tanaka Y, Nishida N, Sugiyama M, et al. Genome-wide association of IL28B with response to pegylated interferon-alpha and ribavirin therapy for chronic hepatitis C. Nat Genet 41: 11051109, 2009.

23. van de Laar TJ, Matthews GV, Prins M, Danta M. Acute hepatitis $\mathrm{C}$ in HIV-infected men who have sex with men: an emerging sexually transmitted infection. AIDS 24: 1799-1812, 2010.

24. Dustin LB, Rice CM. Flying under the radar: the immunobiology of hepatitis C. Annu Rev Immunol 25: 71-99, 2007.

25. Rehermann B, Nascimbeni M. Immunology of hepatitis B virus and hepatitis C virus infection. Nat Rev Immunol 5: 215-229, 2005.

26. Pion M, Jaramillo-Ruiz D, Martinez A, Munoz-Fernandez MA, Correa-Rocha R. HIV infection of human regulatory $\mathrm{T}$ cells downregulates Foxp3 expression by increasing DNMT3b levels and DNA methylation in the FOXP3 gene. AIDS 27: 2019-2029, 2013.

27. Williams SK, Donaldson E, Van der Kleij T, et al. Quantification of hepatic FOXP3+ T-lymphocytes in HIV/hepatitis C coinfection. J Viral Hepat 21: 251-259, 2014.

28. Qurishi N, Kreuzberg C, Luchters G, et al. Effect of antiretroviral therapy on liver-related mortality in patients with HIV and hepatitis C virus coinfection. Lancet 362: 1708-1713, 2003.

29. Macias J, Berenguer J, Japon MA, et al. Fast fibrosis progression between repeated liver biopsies in patients coinfected with human immunodeficiency virus/hepatitis C virus. Hepatology 50: 10561063, 2009.

30. Sulkowski M, Pol S, Mallolas J, et al. Boceprevir versus placebo with pegylated interferon alfa- $2 b$ and ribavirin for treatment of hepatitis $\mathrm{C}$ virus genotype 1 in patients with HIV: a randomised, double-blind, controlled phase 2 trial. Lancet Infect Dis 13: 597-
605, 2013.

31. Carrat F, Bani-Sadr F, Pol S, et al. Pegylated interferon alfa-2b vs standard interferon alfa- $2 b$, plus ribavirin, for chronic hepatitis $\mathrm{C}$ in HIV-infected patients: a randomized controlled trial. JAMA 292: 2839-2848, 2004.

32. Chung RT, Andersen J, Volberding P, et al. Peginterferon Alfa-2a plus ribavirin versus interferon alfa-2a plus ribavirin for chronic hepatitis $\mathrm{C}$ in HIV-coinfected persons. $\mathrm{N}$ Engl J Med 351: 451459, 2004.

33. Manns MP, McHutchison JG, Gordon SC, et al. Peginterferon alfa- $2 \mathrm{~b}$ plus ribavirin compared with interferon alfa- $2 \mathrm{~b}$ plus ribavirin for initial treatment of chronic hepatitis $\mathrm{C}$ : a randomised trial. Lancet 358: 958-965, 2001.

34. Fried MW, Shiffman ML, Reddy KR, et al. Peginterferon alfa-2a plus ribavirin for chronic hepatitis $\mathrm{C}$ virus infection. N Engl $\mathrm{J}$ Med 347: 975-982, 2002.

35. Aranzabal L, Casado JL, Moya J, et al. Influence of liver fibrosis on highly active antiretroviral therapy-associated hepatotoxicity in patients with HIV and hepatitis C virus coinfection. Clin Infect Dis 40: 588-593, 2005.

36. Sulkowski MS, Sherman KE, Dieterich DT, et al. Combination therapy with telaprevir for chronic hepatitis $C$ virus genotype 1 infection in patients with HIV: a randomized trial. Ann Intern Med 159: 86-96, 2013.

37. Dieterich D, Rockstroh JK, Orkin C, et al. Simeprevir (TMC435) with peginterferon/ribavirin in patients coinfected with $\mathrm{HCV}$ genotype-1 and HIV-1: a phase 3 study. Clin Infect Dis 59: 15791587, 2014.

38. Bambha K, Pierce C, Cox C, et al. Assessing mortality in women with hepatitis $\mathrm{C}$ virus and HIV using indirect markers of fibrosis. AIDS 26: 599-607, 2012.

39. Nunes D, Fleming C, Offner G, et al. HIV infection does not affect the performance of noninvasive markers of fibrosis for the diagnosis of hepatitis $\mathrm{C}$ virus-related liver disease. J Acquir Immune Defic Syndr 40: 538-544, 2005.

\section{(C) 2015 The Japanese Society of Internal Medicine http://www.naika.or.jp/imonline/index.html}

